\title{
Hydroxychloroquine reverses the drug resistance of leukemic K562/ADM cells by inhibiting autophagy
}

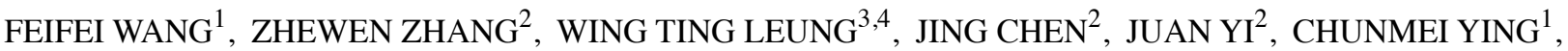

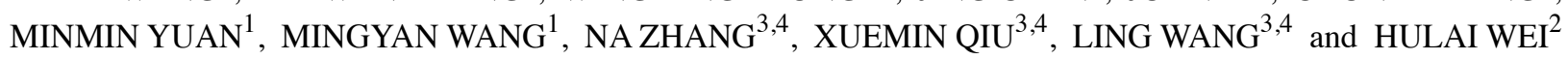 \\ ${ }^{1}$ Department of Laboratory Medicine, Obstetrics and Gynecology Hospital, Fudan University, Shanghai 200011; \\ ${ }^{2}$ Key Laboratory of Preclinical Study for New Drugs of Gansu Province, School of Basic Medical Sciences, \\ Lanzhou University, Lanzhou, Gansu 730000; ${ }^{3}$ Laboratory for Reproductive Immunology, \\ Hospital and Institute of Obstetrics and Gynecology, Fudan University Shanghai Medical College; \\ ${ }^{4}$ Academy of Integrative Medicine, Fudan University, Shanghai 200011, P.R. China
}

Received January 8, 2019; Accepted July 18, 2019

DOI: $10.3892 / \mathrm{mmr} .2019 .10621$

\begin{abstract}
Autophagy is an essential metabolic pathway mediated by lysosomal degradation, which is involved in scavenging and recycling senescent or damaged organelles and biological macromolecules in eukaryotic cells. The present study explored the association between the autophagic activity and chemotherapy resistance of leukaemia cells, and the possibility of using autophagy inhibitors to combat leukemic drug resistance. It was found that the levels of basic autophagy in multidrug-resistant leukaemia cells (K562/ADM) were significantly higher compared with sensitive cells (K562), and that Adriamycin (ADM) was capable of inducing autophagic activity in K562 and K562/ADM cells. K562 and K562/ADM cells were treated with a series of hydroxychloroquine (HCQ) concentrations to inhibit cellular autophagy and detect cell sensitivity to ADM. The results demonstrated that the sensitivity of K562 cells to ADM was mildly enhanced by HCQ, and that the sensitivity of K562/ADM cells to ADM was markedly strengthened by HCQ. In addition, more typical morphological changes associated with apoptosis emerged, and the ratio of $\mathrm{Bax} / \mathrm{Bcl}-2$ and activity of caspase-3 were markedly increased in K562/ADM cells treated with HCQ. Notably, the expression
\end{abstract}

Correspondence to: Professor Hulai Wei, Key Laboratory of Preclinical Study for New Drugs of Gansu Province, School of Basic Medical Sciences, Lanzhou University, 199 Donggang West Road, Lanzhou, Gansu 730000, P.R. China

E-mail: weihulai@lzu.edu.cn

Professor Ling Wang, Laboratory for Reproductive Immunology, Hospital and Institute of Obstetrics and Gynecology, Fudan University Shanghai Medical College, 419 Fangxie Road, Shanghai 200011, P.R. China

E-mail: dr.wangling@fudan.edu.cn

Key words: autophagy, drug resistance, apoptosis, P-glycoprotein, leukaemia of $m d r 1$ mRNA and P-glycoprotein (P-gp) in drug-resistant K562/ADM cells was upregulated along with increasing autophagic activity induced by ADM. Furthermore, HCQ significantly reduced the increase in P-gp expression by inhibiting autophagic activity. Collectively, these findings indicated that the inhibition of autophagy significantly promoted the sensitivity of K562/ADM cells to ADM by facilitating apoptosis. Furthermore, inhibition of autophagy attenuated the expression of P-gp; therefore, P-gp may be involved in autophagic regulation in drug-resistant cells.

\section{Introduction}

Leukaemia, a clonal proliferative neoplasm derived from haematopoietic stem cells, is commonly caused by various genetic mutations (1). There are a variety of clinical therapies involving chemotherapy used to treat leukaemia (2). After prolonged exposure to chemotherapeutic drugs, some patients may develop multidrug resistance, which is defined by resistance to a wide range of functionally unrelated chemotherapeutic agents. Drug resistance hinders chemotherapeutic efficacy and leads to poor prognosis in patients with leukaemia (3). Therefore, there is an urgent requirement for more effective and less toxic drugs to manage chemotherapy-induced multidrug resistance.

The exact mechanism of multidrug resistance is not clear, and previous studies have suggested that it may be partially due to the overexpression of ATP-binding cassette (ABC) transporters, alteration of metabolised enzymes, impaired apoptosis and autophagy, and the existence of leukaemia stem cells (4). P-glycoprotein (P-gp) is one of the most studied $\mathrm{ABC}$ transporters (5), and functions as a transporter to move substrates across cellular membranes using the energy released from ATP hydrolysis (6). The $m d r l$ (multidrug-resistance) gene is located on chromosomal region 7q21 and encodes an amino acid sequence that forms P-gp (170 kDa) after glycosylation (7). P-gp is constitutively expressed in various adult tissues, such as those of the intestine, liver, kidney and brain, where it serves an important role in drug excretion and protects cells from external threats (8). Overexpression of P-gp 
in cancer cells often leads to multidrug resistance by pumping agents out of cells (9).

Apoptosis is a caspase-3-dependent programmed cell death process (10) that is regulated by a variety of elements such as the Bcl-2 protein family (11). The Bcl-2 family includes both pro-apoptotic proteins, such as Bax and Bcl-2 homologous antagonist killer (Bak), and anti-apoptotic proteins, such as Bcl-2 and Bcl-xL (12). Bax/Bak promotes apoptosis by forming homogenous or heterogeneous dimers, and enhancing the permeabilization of the outer mitochondrial membrane. Bcl-2/Bcl-xL can combine with Bax/Bak to suppress the formation of dimers, resulting in apoptosis inhibition $(13,14)$. A number of studies have reported that the ratio of anti-apoptotic to pro-apoptotic protein levels, rather than a single $\mathrm{Bcl}-2$ family protein, determines apoptosis susceptibility (15). Once cancer cells become unsusceptible to chemotherapy-induced apoptosis, they may acquire drug resistance (16).

Autophagy is an evolutionarily conserved process of eukaryotic cells. It enables cells to sequester cellular components by forming a double-membrane vacuole, called an autophagosome, and subsequently to degrade those components after the fusion of autophagosomes with lysosomes (17). The degradation products, including amino acids, fatty acids, nucleotides and ATP, are reused by cells to maintain the cell structure and metabolism (18). In addition to participating in physiological processes, autophagy also serves a vital role in various pathological conditions, such as neurodegenerative disorders, autoimmunity disease, inflammation and cancer (19-22). Evidence suggests that autophagy emerges in a context-dependent role in cancer. On the one hand, autophagy inhibits tumour initiation by cleaning up oncogenic protein substrates, toxic misfolded proteins and dysfunctional organelles (23). On the other hand, once a tumour has been established, autophagy can facilitate tumour survival in an environment of nutrient depletion or hypoxia by catabolising unnecessary proteins into amino acids and generating the energy needed for tumour cell survival, which is associated with the drug resistance of cancer cells (24). However, it has been reported that hyperactive autophagy can induce apoptosis or degrade cytoplasmic contents, thereby resulting in the death of tumour cells $(25,26)$.

In our previous study, it was determined that multidrug-resistant leukaemia cells (K562/ADM cells) demonstrated a higher level of autophagy than drug-sensitive leukaemia cells (K562 cells), both at the basic metabolic state and when under nutrient deprivation stress, implying that autophagy is associated with the drug resistance of leukaemia cells (27). To clarify the mechanism of drug resistance in leukaemia cells, hydroxychloroquine (HCQ), a classic autophagy inhibitor, was used to reverse the drug resistance of K562/ADM cells, increase their apoptosis level and inhibit their P-gp expression. This observation indicated the complicated relationship between autophagy and multidrug resistance, and suggested a novel target for leukaemia intervention.

\section{Materials and methods}

Chemicals and antibodies. HCQ was purchased from the Tokyo Chemical Industry Co., Ltd. Adriamycin (ADM) was obtained from the Kangbaotai Biochemical Industry Company.
Newborn bovine serum was obtained from the Rongye Biotech Company (http://royabio.800400.net). RPMI-1640 medium was acquired from Gibco (Thermo Fisher Scientific, Inc.), MTT from Sigma-Aldrich (Merck KGaA); and TRIzol ${ }^{\circledR}$ was from Invitrogen (Thermo Fisher Scientific, Inc.). Specific primers for $m d r l$ and $\beta$-actin were synthesised by the Takara Bio, Inc. Antibodies against P62 (cat. no. 88588) and light chain (LC)3 (cat. no. 4108) were obtained from Cell Signaling Technology, Inc.; anti- $\beta$-actin antibody (cat. no. A1813) was from BioVision, Inc.; antibodies against Bax (cat. no. TA346891), Bcl-2 (cat. no. TA803003) and cleaved caspase-3 (cat. no. TA336455) were purchased from Beijing Zhongshan Jinqiao Biotechnology Co., Ltd.; anti-P-gp antibody (cat. no. BM4508), horseradish peroxidase (HRP)-linked anti-rabbit (cat. no. BA1054) and anti-mouse (cat. no. BA1050) IgG antibodies were from the Wuhan Boster Biological Technology, Ltd.

Cell lines and culture. The human ADM-resistant leukaemia cell line (K562/ADM cells) and its parental subline (K562 cells) were both provided by the Medical Experimental Center of Lanzhou University. K562/ADM and K562 cells were maintained in RPMI-1640 medium, supplemented with $10 \%$ inactivated newborn bovine serum and $2 \mathrm{mmol} / \mathrm{l} \mathrm{L}$-glutamine, at $37^{\circ} \mathrm{C}$ in a cell incubator with $5 \% \mathrm{CO}_{2}$. Experiments were performed when the cells reached the mid-log phase.

Cell viability assay (MTT assay). K562/ADM and K562 cells were seeded at a density of $1 \times 10^{5}$ cells $/ \mathrm{ml}$ in $96-$ well plates. The cells were treated with $0,2,4,8,16,20$ and $40 \mu \mathrm{mol} / 1$ of HCQ for $24 \mathrm{~h}$ at $37^{\circ} \mathrm{C}$. MTT solution $(10 \mu \mathrm{l} ; 5 \mathrm{~g} / \mathrm{l})$ was added to each well before the cells were incubated at $37^{\circ} \mathrm{C}$ for a further $4 \mathrm{~h}$. Then, $100 \mu \mathrm{l}$ of $10 \%$ acidulated sodium dodecyl sulfate (SDS) were added to each well, which was incubated for $12 \mathrm{~h}$ at $37^{\circ} \mathrm{C}$ to dissolve the formazan crystals. Cell proliferation was then detected by MTT colorimetric assay. The optical density (OD) was measured at $570 \mathrm{~nm}$ using a Powerwave $X$ plate reader (BioTek Instruments, Inc.). Cell proliferation inhibition rates were calculated using the following formula: Cell proliferation inhibition rate $=\left[\left(\mathrm{OD}_{\text {control }}-\mathrm{OD}_{\text {experiment }}\right) / \mathrm{OD}_{\text {control }}\right] \times 100 \% .4$ and $16 \mu \mathrm{mol} / 1$ of HCQ were selected as the maximum non-toxic concentration to treat with K562 and K562/ADM cells in the following experiments. Cells were seeded in 96-well plates at a density of $1 \times 10^{5}$ cells $/ \mathrm{ml}$ in triplicate and were cultured with ADM or/and HCQ at the indicated concentrations at $37^{\circ} \mathrm{C}$ for 12,24 or $48 \mathrm{~h}$. K562 cells were treated with $0,0.09,0.18$, $0.375,0.75,1.5 \mu \mathrm{mol} / 1$ of ADM or pretreated with $4 \mu \mathrm{mol} / 1$ of HCQ for $3 \mathrm{~h}$ before exposure to ADM. K562/ADM cells were treated with $0,1.5,3,6,12,24 \mu \mathrm{mol} / 1$ of ADM or pretreated with $16 \mu \mathrm{mol} / \mathrm{l}$ of HCQ for $3 \mathrm{~h}$ before exposure to ADM, and then MTT assay was executed as above. The half-maximal inhibitory concentration $\left(\mathrm{IC}_{50}\right)$ was calculated using cell proliferation inhibition rate by SPSS 17.0 software (SPSS, Inc.). All samples were prepared in triplicate.

Acridine orange $(A O)$ and ethidium bromide $(E B)$ staining. $\mathrm{AO}$ and EB staining have been used to discriminate normal cells from those undergoing apoptosis and death (28). K562/ADM and K562 cells were treated with 35 and $0.75 \mu \mathrm{mol} / 1$ of $\mathrm{ADM}$, respectively, for $24 \mathrm{~h}$ or pretreated with HCQ (16 and $4 \mu \mathrm{mol} / \mathrm{l}$, respectively) for $3 \mathrm{~h}$ prior to exposure to ADM. Cells were 
harvested and washed twice with PBS. After being suspended in $100 \mu \mathrm{l}$ of $\mathrm{PBS}$, the cells were stained with $5 \mu \mathrm{l}$ of EB $(200 \mathrm{mg} / \mathrm{l})$ and $5 \mu \mathrm{l}$ of $\mathrm{AO}(200 \mathrm{mg} / \mathrm{l})$ for $30 \mathrm{~min}$ at $37^{\circ} \mathrm{C}$ in the dark. Subsequently, the cells were rinsed with PBS three times, and a drop of suspension was placed on a glass slide. Cells were observed under a fluorescence microscope (Olympus Corporation) with a blue filter in fields with $\mathrm{x} 400$ magnification.

Detection by transmission electron microscopy. K562/ADM and K562 cells were treated with 35 and $0.75 \mu \mathrm{mol} / 1$ of ADM, respectively, for $24 \mathrm{~h}$ or pretreated with HCQ (16 and $4 \mu \mathrm{mol} / \mathrm{l}$, respectively) for $3 \mathrm{~h}$ prior to exposure to ADM. Cells were fixed with glutaraldehyde at $4^{\circ} \mathrm{C}$ overnight. The next day, after rinsing with PBS three times for $5 \mathrm{~min}$, cells were fixed with $1 \% \mathrm{OsO}_{4}$ at room temperature for $1.5 \mathrm{~h}$. After dehydration, cells were embedded in epoxy resin and then solidified for $12 \mathrm{~h}$ at $45^{\circ} \mathrm{C}$. After being sliced into $70 \mathrm{~nm}$-thick sections, the cells were stained with $2 \%$ uranyl acetate for $30 \mathrm{~min}$ and $2 \%$ lead citrate for $15 \mathrm{~min}$ at $37^{\circ} \mathrm{C}$. Finally, the ultrastructure of the cells was observed under a JEM1230 transmission electron microscope in fields with $\mathrm{x} 8,000$ magnification (JEOL, Ltd.).

Flow cytometry. K562/ADM and K562 cells were treated with 35 and $0.75 \mu \mathrm{mol} / 1$ of ADM, respectively, for $24 \mathrm{~h}$ or pretreated with HCQ (16 and $4 \mu \mathrm{mol} / \mathrm{l}$, respectively) for $3 \mathrm{~h}$ prior to exposure to ADM. For the determination of Bax and Bcl-2 levels, $1 \times 10^{6}$ cells were fixed with $200 \mu \mathrm{l}$ of an acetone and glutaraldehyde mixture (1:1) for $20 \mathrm{~min}$ at $4^{\circ} \mathrm{C}$. After rinsing with PBS, each sample was incubated with anti-Bax FITC (1:20, cat. no. DB1010, DB Biotech) or anti-Bcl-2 FITC (1:20, cat. no. DB1011) for $15 \mathrm{~min}$ in $100 \mu \mathrm{l}$ of PBS in the dark at room temperature, and then suspended in $500 \mu \mathrm{l}$ of PBS. For detection of P-gp expression, cells were collected and washed with PBS, and then incubated with antibodies against P-gp (1:20, cat. no. ab93590, Abcam) for $15 \mathrm{~min}$ in the dark. After rinsing with PBS, cells were suspended in $500 \mu \mathrm{l}$ of PBS. To analyse caspase- 3 activity, $1 \mu 1$ of FITC-DEVD-FMK (1:100, cat. no. QIA911KIT, Sigma-Aldrich; Merck KGaA) was added to cell suspensions in $100 \mu \mathrm{l}$ of washing buffer. After incubation for $30 \mathrm{~min}$ at $37^{\circ} \mathrm{C}$, the cells were washed and suspended in $500 \mu \mathrm{l}$ of washing buffer. After treatment, these samples were analysed using a flow cytometer (Beckman Coulter, Inc.) and analysed using Windows Multiple Document Interface for Flow Cytometry software (version 2.8; The Scripps Research Institute, La Jolla, CA, USA).

Reverse transcription-quantitative polymerase chain reaction (RT-qPCR). K562/ADM and K562 cells were treated with 35 and $0.75 \mu \mathrm{mol} / 1$ of $\mathrm{ADM}$, respectively, for $24 \mathrm{~h}$ or pretreated with HCQ (16 and $4 \mu \mathrm{mol} / 1$, respectively) for $3 \mathrm{~h}$ prior to exposure to ADM. A total of $1 \times 10^{6}$ cells were collected, and then total RNA was extracted from cells with a TRIzol kit according to the manufacturer's protocols. Both the concentrations and purity of the extracted RNA samples were determined by spectrophotometry. Subsequently, $500 \mathrm{ng}$ of each RNA sample was converted into cDNA using a Prime Script RT Master Mix (Takara Bio, Inc.). Temperature protocol: $70^{\circ} \mathrm{C}$ for $30 \mathrm{~min}$, $37^{\circ} \mathrm{C}$ for $15 \mathrm{~min}, 95^{\circ} \mathrm{C}$ for $5 \mathrm{~min}$. qPCR assays were performed on a Rotor-Gene 3000 quantitative PCR amplifier (Corbett, Australia) with a SYBR Premix Taq II kit (Takara) and primers. The following primers were used: $m d r l$ forward, 5'-CTCATAATTCCATTAGGACG-3'; $m d r l$ reverse, 5'-GCT CACGCTACAGGTCCTGT-3'; $\beta$-actin forward, 5'-TGCTC CTCCTGAGCGCAAGTA-3'; and $\beta$-actin reverse, 5'-CCA CATCTGCTGGAAGGTGGA-3'. The conditions included an initial denaturing step at $95^{\circ} \mathrm{C}$ for $10 \mathrm{sec}$, then 40 cycles of denaturing at $95^{\circ} \mathrm{C}$ for $5 \mathrm{sec}$ and annealing at $60^{\circ} \mathrm{C}$ for $30 \mathrm{sec}$. The relative expression of each mRNA was calculated by comparison to $\beta$-actin mRNA using the $2^{-\Delta \Delta \mathrm{Cq}}$ method (29). All samples were prepared in triplicate.

Western blotting. K562/ADM and K562 cells were treated with 35 and $0.75 \mu \mathrm{mol} / 1$ of ADM, respectively, for $24 \mathrm{~h}$ or pretreated with HCQ (16 and $4 \mu \mathrm{mol} / 1$, respectively) for $3 \mathrm{~h}$ prior to exposure to ADM. Cells were lysed in RIPA lysis buffer with phenylmethanesulfonyl fluoride (PMSF; $\mathrm{PMSF} / \mathrm{RIPA}=1: 100$ ) for $30 \mathrm{~min}$ on ice and then centrifuged at $16,000 \mathrm{x} \mathrm{g}$ and $4^{\circ} \mathrm{C}$ for $15 \mathrm{~min}$. The protein concentration of the supernatant was measured using a bicinchoninic acid protein assay kit. Equal amounts of protein $(40 \mu \mathrm{g})$ from cell extracts were separated via 10\% SDS-PAGE and transferred onto PVDF membranes. After blocking with $5 \%$ defatted milk in PBST at $24^{\circ} \mathrm{C}$ for $1 \mathrm{~h}$, the membranes were incubated with primary antibodies including anti-P62 (1:500), anti-LC3 (1:2,000), anti-Bax (1:1,000), anti-Bcl-2 (1:1,000), anti-cleaved Caspase-3 (1:1,000), anti-P-gp (1:500) and anti- $\beta$-actin $(1: 1,000)$ at $4^{\circ} \mathrm{C}$ overnight and then with HRP-conjugated secondary antibodies $(1: 10,000)$. Finally, the protein bands of the immunoblot were determined using a chemiluminescent approach in a dark room. Protein bands were visualized using enhanced chemiluminescence reagents (EMD Millipore). Western blots were scanned using an Infrared Imaging System (LI-COR Biosciences) and the bands were quantified using ImageJ software (version 1.45S; National Institutes of Health).

Statistical analysis. Student's t-test or one-way ANOVA was conducted to compare the differences in continuous data. Bonferroni correction was employed to determine the significance of differences between two groups. All statistical analyses were conducted by using SPSS 17.0 software (SPSS, Inc.). All statistical analyses were two-sided, and the results are all presented as the mean \pm the standard deviation of at least three independent experiments. $\mathrm{P}<0.05$ was considered to indicate a statistically significant difference.

\section{Results}

Overexpression of $P$-gp and increased autophagic activity co-occur in K562/ADM cells. To investigate the differences in P-gp levels between K562/ADM and K562 cells, P-gp protein expression levels were detected via flow cytometric analysis. As shown in Fig. 1A, the positive rate and mean fluorescence intensity of P-gp were both markedly elevated in K562/ADM cells compared with K562 cells. Similar results were observed with a western blotting assay (Fig. 1B), which indicated that K562/ADM cells exhibited notably higher P-gp protein expression levels compared with K562 cells. Furthermore, the basic autophagic activities of K562/ADM and K562 cells were measured. After observation of autophagosomes in cells under a transmission electron microscope, 
A

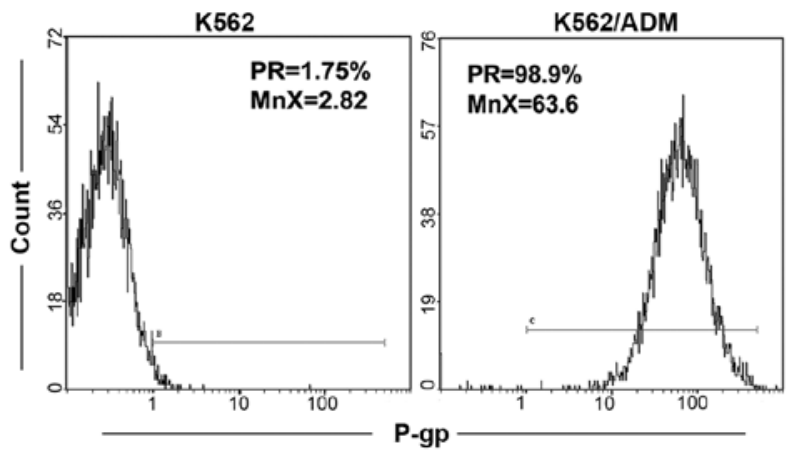

B
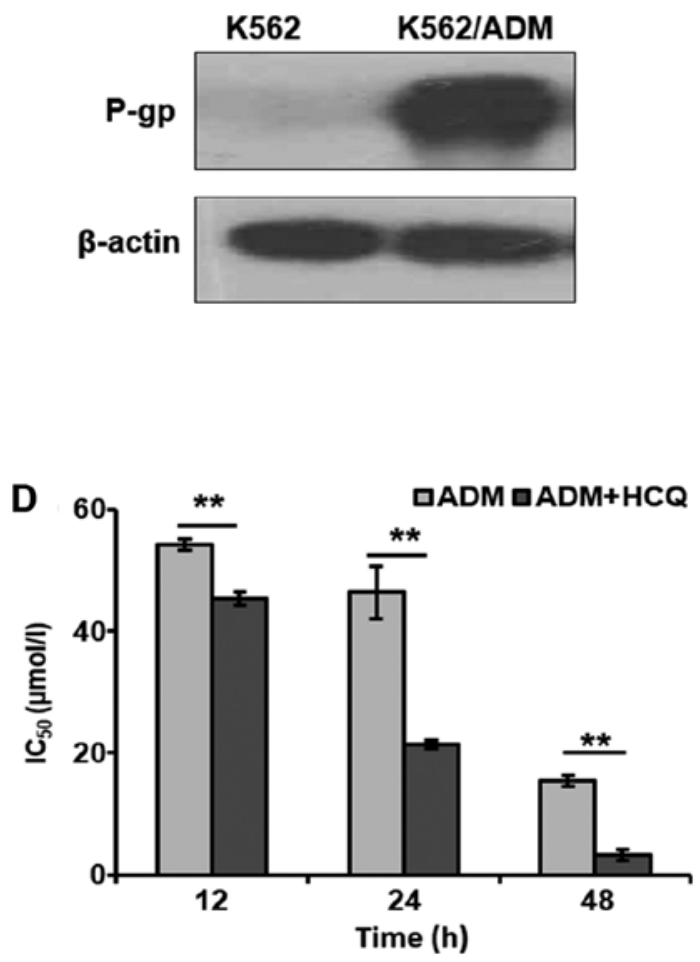
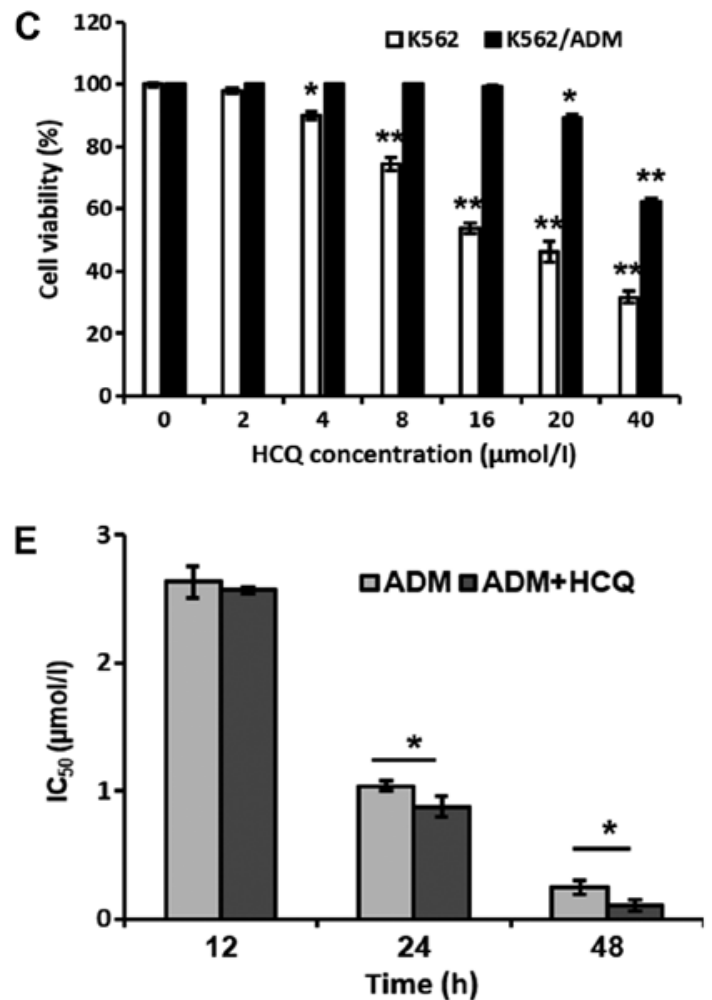

Figure 1. HCQ selectively enhances the cytotoxic effects of ADM in K562/ADM cells. (A) P-gp protein levels were detected via flow cytometry. (B) P-gp protein expression was evaluated via western blot analysis. (C) K562/ADM and K562 cells were treated with different concentrations of HCQ for 24 h, and the cell viability was analysed by an MTT assay. The control group was treated with $0 \mu \mathrm{mol} / 1 \mathrm{HCQ}$. ${ }^{*} \mathrm{P}<0.05$ and ${ }^{* *} \mathrm{P}<0.01$ vs. control group for corresponding cells. (D) K562/ADM and (E) K562 cells were treated with different concentrations of ADM alone or following pre-treatment with HCQ (16 and $4 \mu$ mol/1, respectively) for $3 \mathrm{~h}$ before exposure to $\mathrm{ADM}$ for 12,24 or $48 \mathrm{~h}$. Then, cell viability was detected by an $\mathrm{MTT}$ assay. $\mathrm{IC}_{50}$ values of $\mathrm{ADM}$ in $\mathrm{K} 562 / \mathrm{ADM}$ and K562 cells were determined. Data are presented as the mean \pm the standard deviation of four separate experiments. ${ }^{*} \mathrm{P}<0.05$, ${ }^{* *} \mathrm{P}<0.01$. HCQ, hydroxychloroquine; ADM, Adriamycin; P-gp, P-glycoprotein.

more cytosolic contents-packaged autophagic vacuoles were identified in K562/ADM cells compared with K562 cells (Fig. 2A). To further verify the results described above, other autophagic indicators were examined, such as LC3 and P62 (also known as sequestosome-1). As we know, the ratio of LC3-II to LC3-I will become larger when the quantity of autophagosomes increases, and P62, a ubiquitination substrate, has a contrary relationship with autophagic activity (27). As presented in Fig. 2B and C, K562/ADM cells demonstrated a notably increased LC3-II/LC3-I ratio and decreased P62 levels compared with K562 cells, indicating that K562/ADM cells exhibited a higher level of autophagic flux.

HCQ enhances the cytotoxic effects of $A D M$ in K562/ADM cells. Different concentrations of HCQ were used to investigate its cytotoxic effects on K562/ADM and K562 cells using an MTT assay. As presented in Fig. 1C, HCQ inhibited the viability of K562/ADM and K562 cells in a dose-dependent manner. K562 and K562/ADM cells demonstrated almost no cytotoxicity (cell viability $>80 \%$ ) following treatment with 4 and $16 \mu \mathrm{mol} / 1$ of $\mathrm{HCQ}$, respectively, which were selected as the maximum non-toxic concentrations in the following experiments. Then, K562/ADM and K562 cells were treated with different concentrations of ADM alone or following pre-treatment with HCQ (16 and $4 \mu \mathrm{mol} / \mathrm{l}$, respectively) for $3 \mathrm{~h}$ prior to exposure to ADM for 12, 24 or $48 \mathrm{~h}$. It was identified that the $\mathrm{IC}_{50}$ values for $\mathrm{ADM}$ in K562/ADM cells following HCQ treatment for 12, 24 and $48 \mathrm{~h}$ were $45.66 \pm 5.08,21.44 \pm 0.59$ and $3.26 \pm 0.86 \mu \mathrm{mol} / 1$, respectively, which were $0.84-, 0.46$ - and 0.21 -fold less 
A

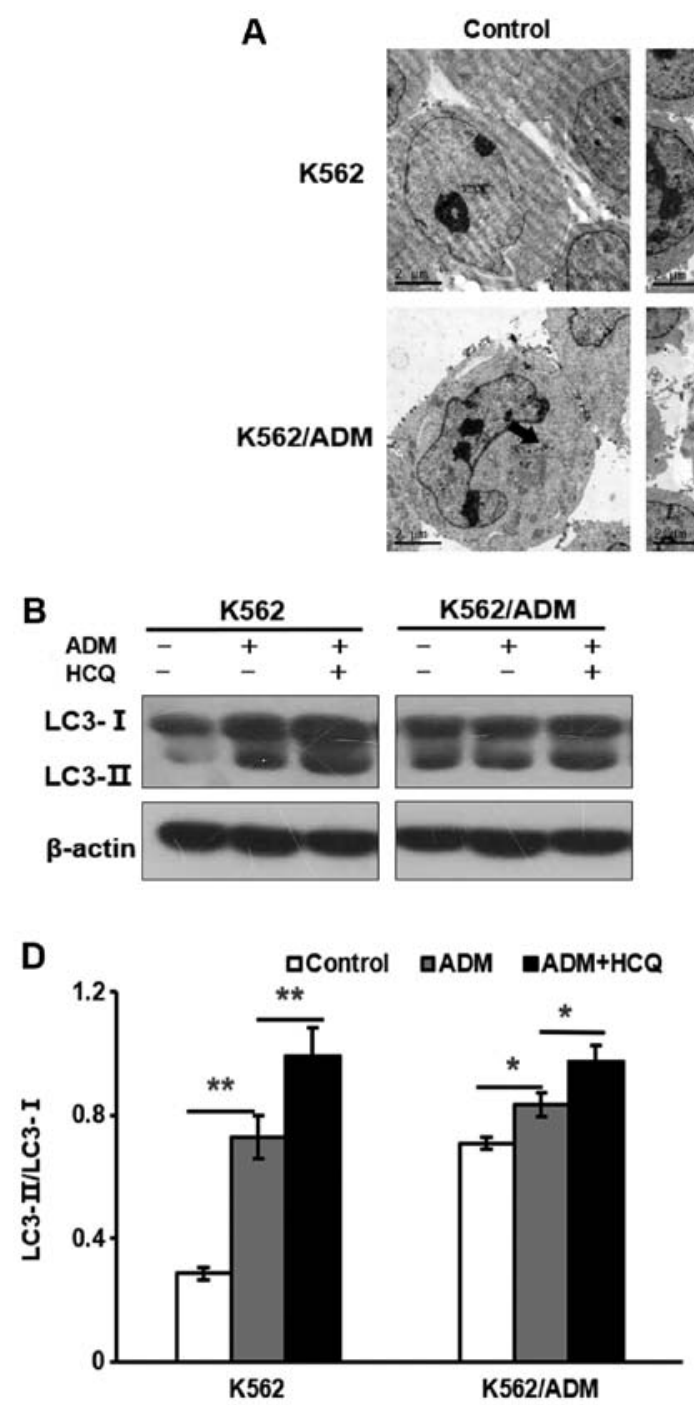

ADM

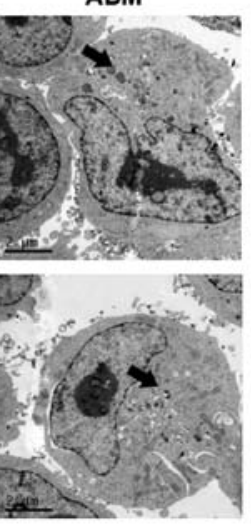

C

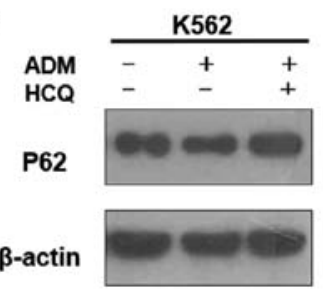

$\mathrm{ADM}+\mathrm{HCQ}$

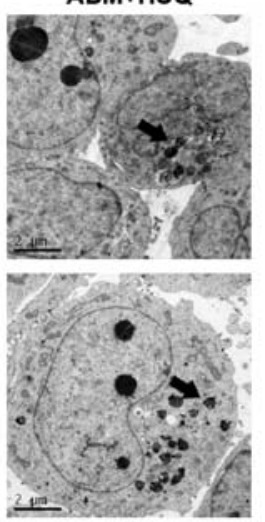

E

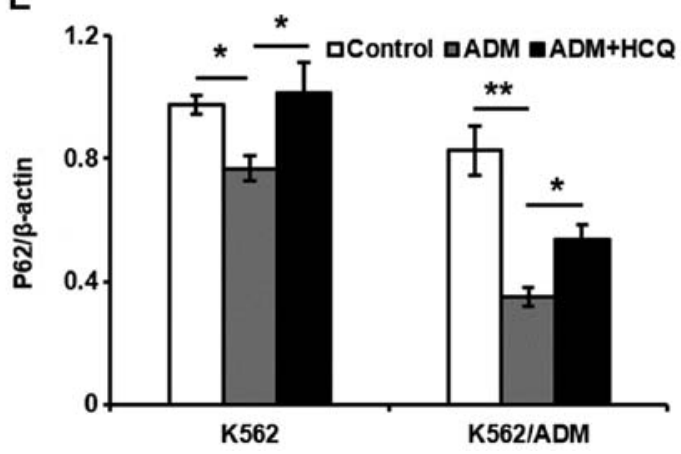

Figure 2. HCQ reduces ADM-induced autophagy in K562 and K562/ADM cells. K562/ADM and K562 cells were treated with 35 and 0.75 $\mu$ mol/1 of ADM, respectively, alone for $24 \mathrm{~h}$ or following pre-treatment with HCQ (16 and $4 \mu \mathrm{mol} / \mathrm{l}$, respectively) for $3 \mathrm{~h}$ prior to exposure to ADM for $24 \mathrm{~h}$. (A) Cellular ultrastructure was observed by transmission electron microscopy (magnification, x8,000). Western blot analysis of (B) the LC3-II/LC3-I ratio and (C) the expression levels of P62 was performed on cell lysates. (D) Densitometric analysis of LC3-II/LC3-I was normalised to $\beta$-actin. (E) Densitometric analysis of P62 was normalised to $\beta$-actin. Data are presented as the mean \pm the standard deviation of three separate experiments. ${ }^{*}<0.05$, ${ }^{* *} \mathrm{P}<0.01$. HCQ, hydroxychloroquine; ADM, Adriamycin; LC, light chain.

than those values after only ADM treatment (Fig. 1D). By contrast, HCQ slightly decreased the $\mathrm{IC}_{50}$ values for ADM in K562 cells (Fig. 1E). These results indicated that HCQ could effectively reverse the ADM resistance of K562/ADM cells.

$H C Q$ reduces $A D M$-induced autophagy in $K 562$ and K562/ADM cells. To investigate the effect of ADM on autophagy, K562/ADM and K562 cells were treated with 35 and $0.75 \mu \mathrm{mol} / 1$ of ADM, respectively, for $24 \mathrm{~h}$ or pretreated with HCQ (16 and $4 \mu \mathrm{mol} / 1$, respectively) for $3 \mathrm{~h}$ prior to exposure to ADM. Then, they were observed under a transmission electron microscope for autophagic vacuoles. As presented in Fig. 2A, more autophagic vacuoles (indicated by black arrows) were found in ADM-treated cells than in the controls, and HCQ increased the number of autophagic vacuoles in K562 and K562/ADM cells treated with ADM. To further validate these results, the levels of the autophagy markers LC3 and P62 were analysed using a western blotting assay. It was found that ADM induced autophagy in K562 and K562/ADM cells, as indicated by the increased LC3-II/LC3-I ratios $(\mathrm{P}=0.001$ and 0.023 , respectively; Fig. $2 \mathrm{~B}$ and $\mathrm{D})$ and a decrease in the $\mathrm{P} 62$ level $(\mathrm{P}=0.023$ and 0.001 , respectively; Fig. $2 \mathrm{C}$ and $\mathrm{E})$. Furthermore, HCQ increased the accumulation of LC3-II $(\mathrm{P}=0.009$ and 0.012 , respectively) and $\mathrm{P} 62(\mathrm{P}=0.012$ and 0.022 , respectively) in both K562 and K562/ADM cells exposed to ADM, indicating that HCQ reduced autophagy activity induced by ADM. Collectively, these findings indicated that HCQ can inhibit the ADM-induced autophagy response in K562 and K562/ADM cells by preventing the degradation of autophagic vacuoles.

HCQ potentiates ADM-induced apoptosis in K562/ADM cells. To explore the apoptosis response in two cell lines following ADM exposure, K562/ADM and K562 cells were treated with 35 and $0.75 \mu \mathrm{mol} / 1$ of ADM separately for $24 \mathrm{~h}$ and stained with $\mathrm{AO} / \mathrm{EB}$. Observed under a fluorescence microscope, 

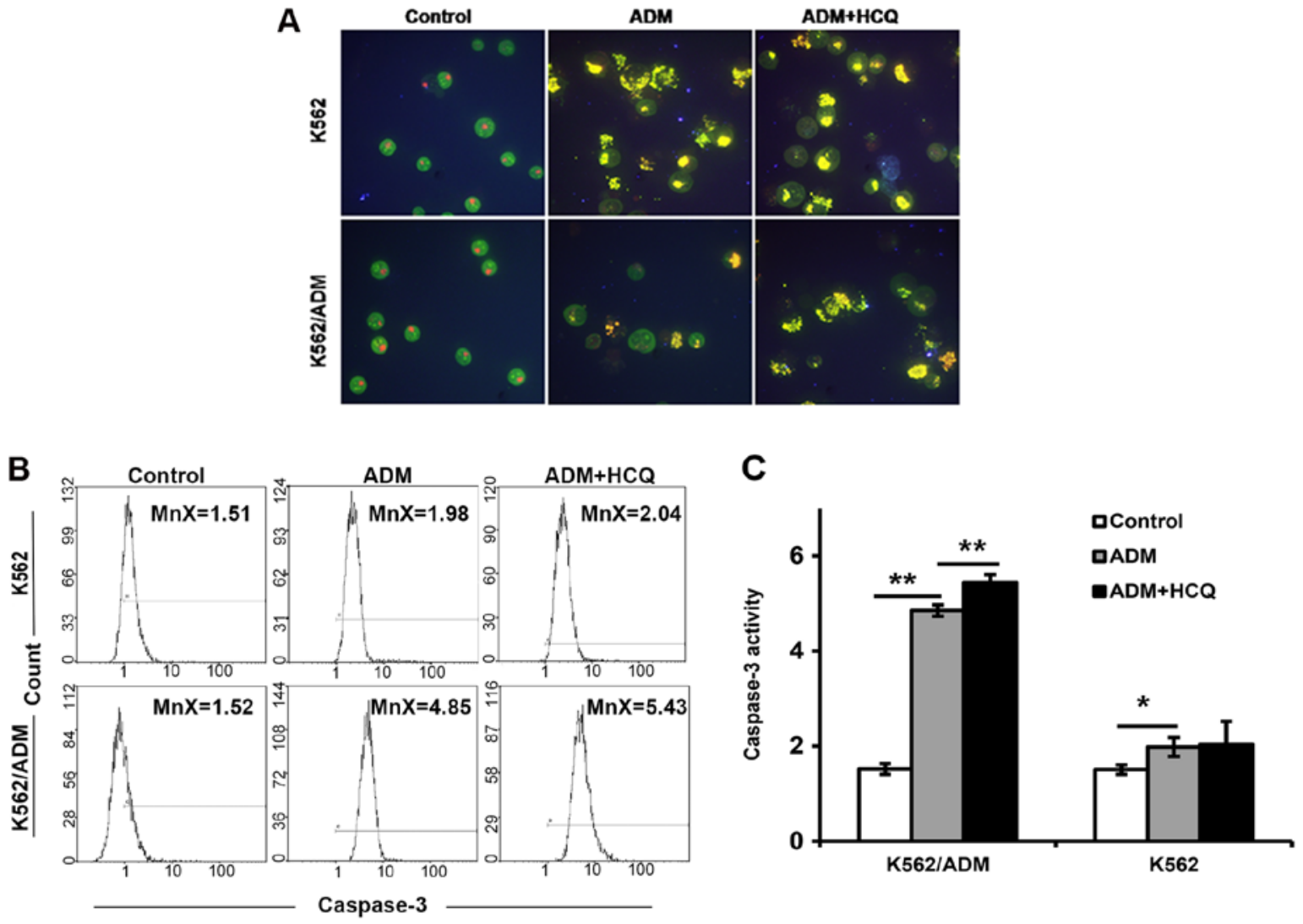

D

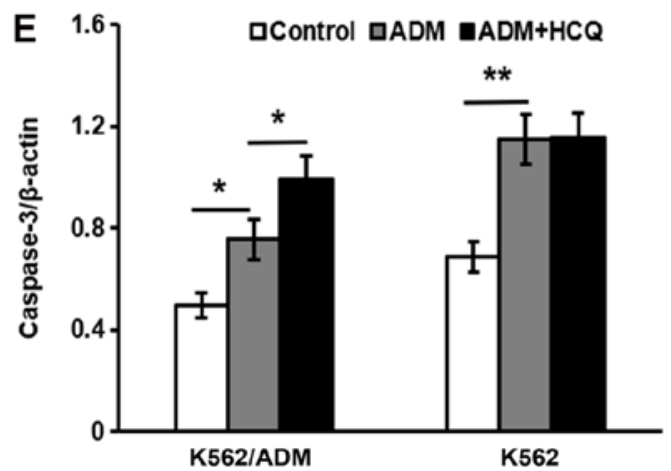

Figure 3. HCQ potentiates caspase-3-mediated apoptosis in K562/ADM cells exposed to ADM. K562/ADM and K562 cells were treated with 35 and $0.75 \mu$ mol/1 of ADM, respectively, alone for $24 \mathrm{~h}$ or following pre-treatment with HCQ (16 and $4 \mu \mathrm{mol} / 1$, respectively) for $3 \mathrm{~h}$ prior to exposure to ADM for $24 \mathrm{~h}$. (A) Cells were treated as aforementioned, and then stained with acridine orange/ethidium bromide and observed under a fluorescence microscope with a blue filter (magnification, x400). (B and C) Caspase-3 activity was detected by flow cytometry. (D) Expression of cleaved caspase-3 was analysed by western blotting. (E) Densitometric analysis of cleaved caspase-3 was normalised to $\beta$-actin. Data are presented as the mean \pm standard deviation of three separate experiments. ${ }^{*} \mathrm{P}<0.05,{ }^{* *} \mathrm{P}<0.01$. HCQ, hydroxychloroquine; ADM, Adriamycin.

the controls exhibited green-stained integral nuclei, whereas yellow or orange nuclei with condensed and fragmentary chromatin were found in cells treated with ADM, suggesting that ADM induced apoptosis in the two cell lines. Furthermore, when cells were pretreated with HCQ for $3 \mathrm{~h}$ prior to exposure to ADM, the proportion of apoptotic K562/ADM cells was notably increased compared with those treated only with ADM; however, the effects of HCQ pre-treatment on the apoptosis of K562 cells were not pronounced (Fig. 3A). Morphological changes indicated that HCQ upregulated ADM-induced apoptosis in K562/ADM.

To confirm these apparent changes in apoptosis, caspase-3 activity was evaluated using flow cytometry, and the expression of the cleaved forms of caspase- 3 was detected via western blotting. As presented in Fig. 3B and C, ADM led to an increased mean fluorescence intensity for activated caspase-3 in $\mathrm{K} 562(\mathrm{P}=0.032)$ and $\mathrm{K} 562 / \mathrm{ADM}(\mathrm{P}=0.001)$ cells. K562/ADM cells pre-treated with HCQ prior to exposure to ADM exhibited a significantly greater mean fluorescence intensity for activated caspase-3 compared with cells exposed to only ADM ( $\mathrm{P}=0.007)$, whereas K562 cells were not significantly affected by HCQ pre-treatment. Similar results were also obtained from the western blot assay (Fig. 3D and E).

These results were verified by the determination of the protein expression levels of Bax/Bcl-2. Flow cytometry demonstrated 

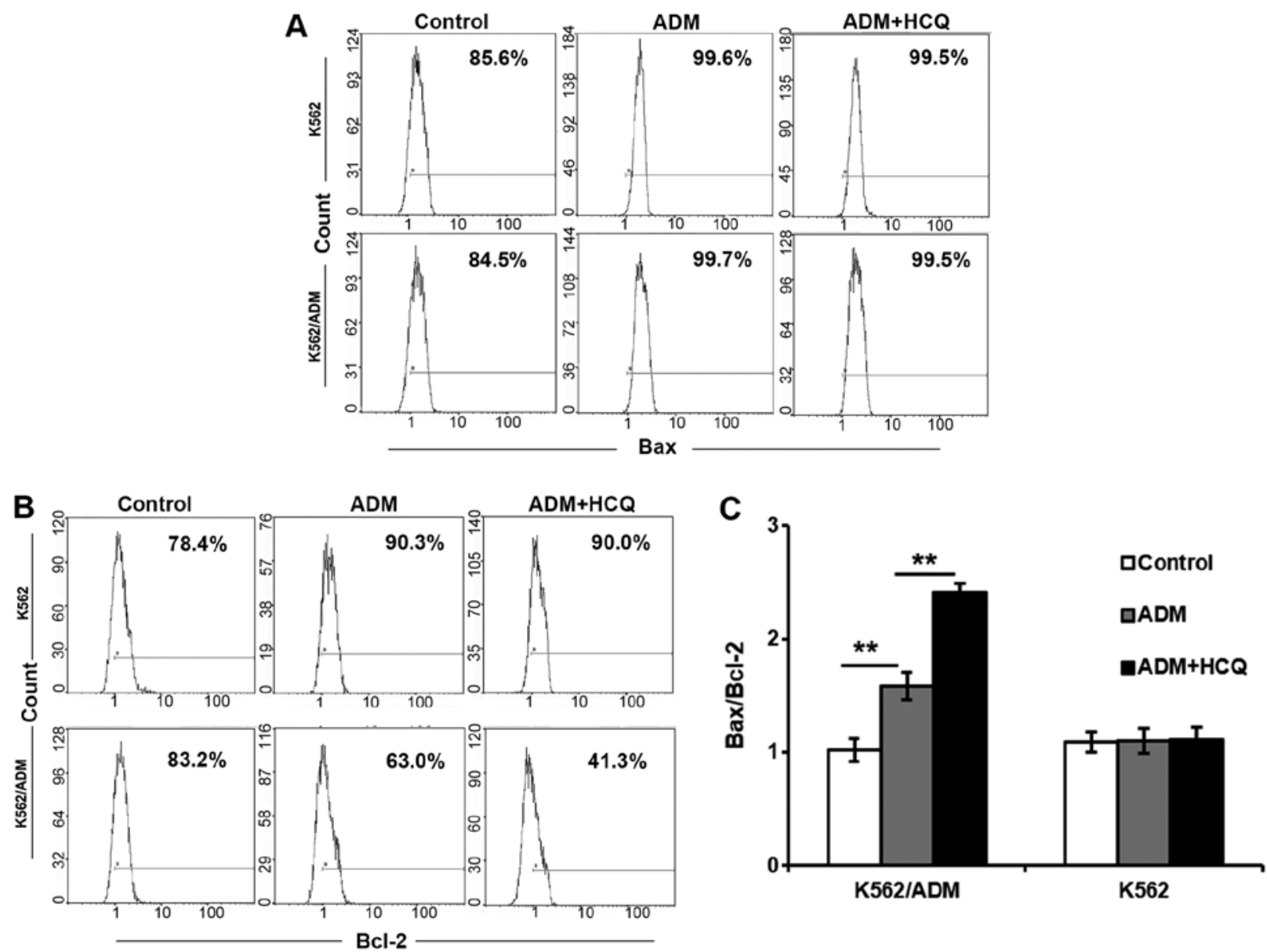

D

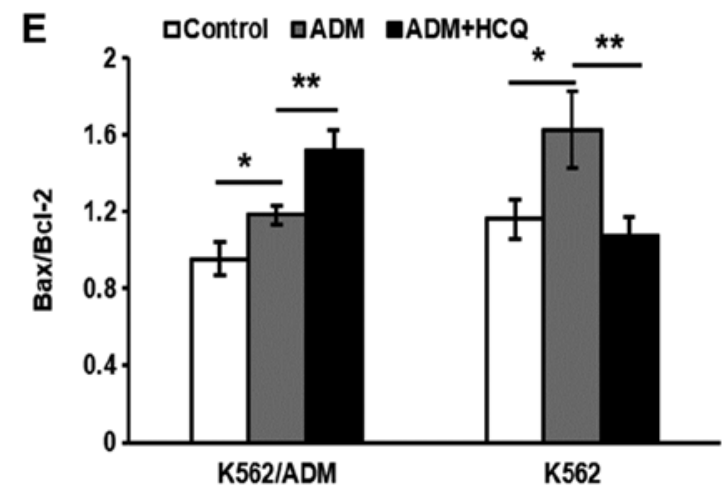

Figure 4. HCQ upregulates the ratio of Bax/ Bcl-2 in K562/ADM cells exposed to ADM. K562/ADM and K562 cells were treated with 35 and $0.75 \mu$ mol/1 of ADM, respectively, alone for $24 \mathrm{~h}$ or following pre-treatment with HCQ (16 and $4 \mu \mathrm{mol} / 1$, respectively) for $3 \mathrm{~h}$ prior to exposure to ADM for $24 \mathrm{~h}$. Expression of (A) Bax and (B) Bcl-2 was quantified via flow cytometry. (C) Ratio of Bax/Bcl-2, as determined via flow cytometry. (D) Expression levels of Bax and Bcl-2 were quantified via western blot analysis. (E) Densitometric analysis of Bax/Bcl-2 was normalised to $\beta$-actin. Data are presented as the mean \pm standard deviation of three separate experiments. ${ }^{*} \mathrm{P}<0.05,{ }^{* *} \mathrm{P}<0.01$. HCQ, hydroxychloroquine; ADM, Adriamycin.

that the ratio of Bax/Bcl-2 was upregulated in K562/ADM cells by $\operatorname{ADM}(\mathrm{P}=0.001)$, which could be further enhanced following $3 \mathrm{~h}$ of HCQ pre-treatment $(\mathrm{P}=0.001$; Fig. $4 \mathrm{~A}-\mathrm{C})$. However, there were no notable effects on K562 cells. The results of the western blot assay of K562/ADM cells were also consistent with these observations, but the situations of K562 cells were incompatible between the flow cytometry and western blotting results (Fig. 4D and E). The change of K562 cells may be induced by other causes in addition to apoptosis. Collectively, these findings indicate that HCQ could sensitise K562/ADM cells to caspase-dependent apoptosis induced by ADM, thereby reversing multidrug resistance.
HCQ diminishes the expression of P-gp in K562/ADM cells exposed to $A D M$. To further clarify the role of autophagic activity in multidrug resistance, the present study modulated autophagy and observed alterations in the expression of the drug resistance-associated protein P-gp during the autophagy process. ADM (35 $\mu \mathrm{mol} / \mathrm{l})$ was used to induce the autophagic response, and $16 \mu \mathrm{mol} / 1 \mathrm{HCQ}$ was used to block autophagy in K562/ADM cells. As demonstrated by a western blot assay, $\mathrm{P}$-gp expression in K562/ADM cells was increased in the presence of ADM $(\mathrm{P}=0.004)$, and $3 \mathrm{~h}$ HCQ treatment decreased ADM-induced $\mathrm{P}$-gp expression to a level similar to that of control treatment $(\mathrm{P}=0.011$; Fig. $5 \mathrm{~A}$ and $\mathrm{B})$. A flow cytometric 
A

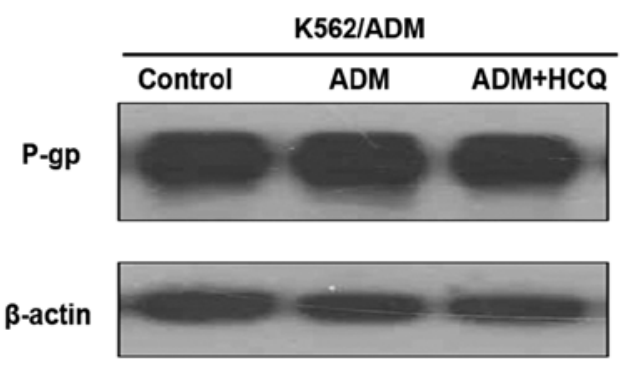

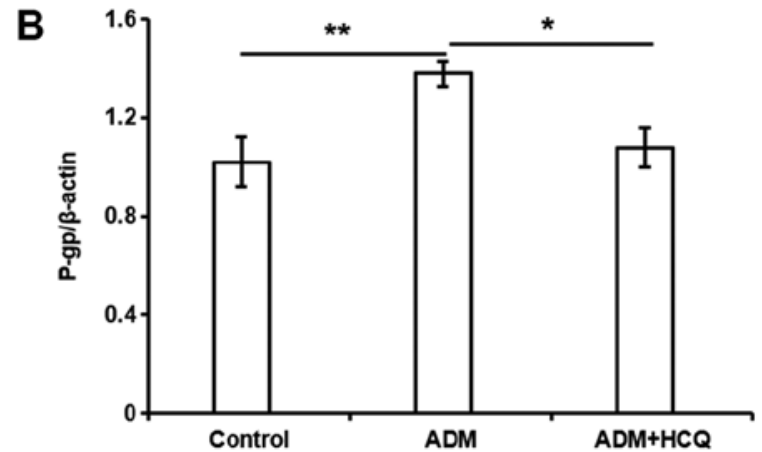
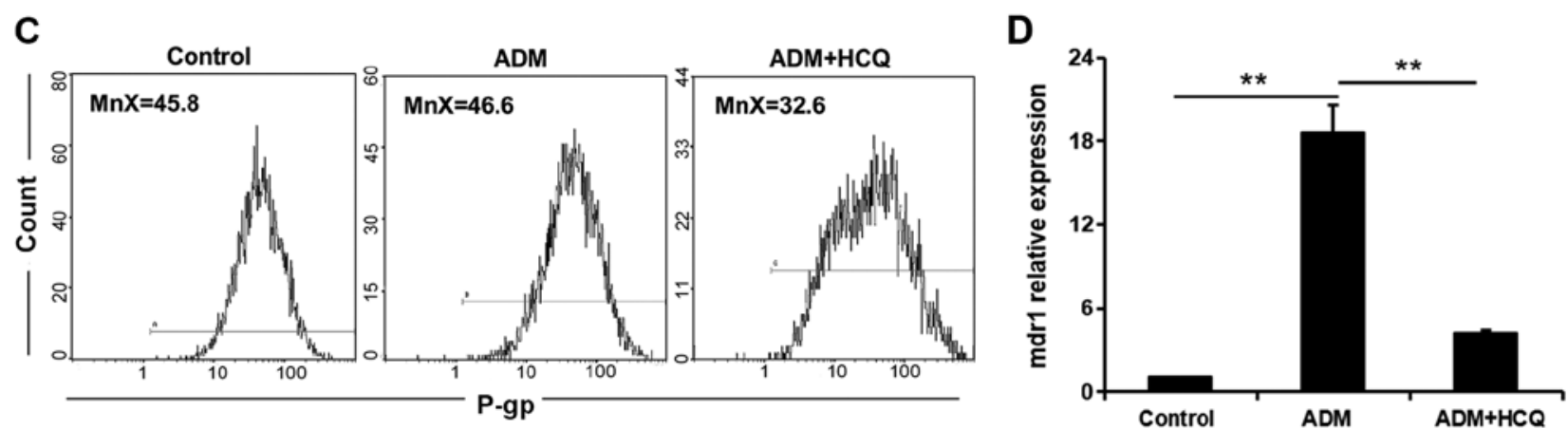

Figure 5. HCQ diminishes the expression of P-gp in K562/ADM cells exposed to ADM. K562/ADM cells were treated with ADM alone for $24 \mathrm{~h}$ or following pre-treatment with HCQ for $3 \mathrm{~h}$ prior to exposure to ADM for $24 \mathrm{~h}$. (A) Expression of P-gp was detected via western blotting. (B) Densitometric analysis of P-gp expression was normalised to $\beta$-actin. (C) Expression of P-gp was detected via flow cytometry. (D) Relative expression of $m d r l$ was quantified via reverse transcription-quantitative PCR. Values are presented as the mean \pm standard deviation of three separate experiments. ${ }^{*} \mathrm{P}<0.05,{ }^{* *} \mathrm{P}<0.01$. $\mathrm{HCQ}$, hydroxychloroquine; P-gp, P-glycoprotein; ADM, Adriamycin.

assay validated this observation, as a slight increase in the mean fluorescence intensity for P-gp was found in K562/ADM cells following ADM incubation, which fell with HCQ treatment (Fig. 5C). In addition, the mRNA expression profile of the $m d r l$ gene in K562/ADM cells following the aforementioned treatments, as determined via RT-qPCR analysis, was consistent with P-gp expression (Fig. 5D). Collectively, these findings indicated that the inhibition of autophagy diminished the expression of P-gp, which may be involved in autophagic regulation in K562/ADM cells.

\section{Discussion}

Leukaemia is a highly malignant cancer of the blood system characterised by rapid onset, poor prognosis and high cost of treatment (30). It is known that leukaemia is a malignancy with one of the highest mortality rates (31). Although there are a variety of chemotherapy drugs for use against leukaemia, chemotherapy-induced multidrug resistance is still a challenging issue during drug treatment (31). Therefore, more effective clinical therapies are needed to conquer the drug resistance induced by chemotherapy.

K562/ADM cells are a multidrug-resistant leukaemia cell line with high expression of $\mathrm{P}$-gp, and are acquired by exposing K562 cells to step-wise increasing concentrations of ADM (32). They are characterised by their resistance not only to ADM but also to other anticancer drugs with varying structures and functions (32). The results of the present study demonstrated that K562/ADM cells exhibited a high level of P-gp expression, while K562 cells expressed minimal levels of
$\mathrm{P}$-gp, indicating that K562/ADM cells are a multidrug-resistant cell line and that K562 is a sensitive cell strain. In addition, it was identified that basic autophagy activity in K562/ADM cells was distinctly higher than it was in K562 cells, which suggests that autophagy may be involved in multidrug resistance. This result is consistent with our previous study (27).

It is well known that autophagy serves a dual role in tumorigenesis. It has been suggested that, in cancer cells, certain chemotherapeutics are able to induce autophagic cell death (ACD), a cell death pathway distinct from apoptosis. Puissant et al (26) reported that resveratrol treatment could lead to ACD in chronic myelogenous leukaemia (CML) cells, and that autophagy inhibition decreased the sensitivity of CML cells to resveratrol. Li et al (33) suggested that 3-methyladenine, an autophagy inhibitor, could promote Raji cell proliferation by restraining the ACD induced by arsenic trioxide. However, in the majority of established tumours, autophagy protects against the survival of cancer cells and confers resistance to chemotherapy. Han et al (34) reported that daunorubicin initiated protective autophagy in acute myelocytic leukaemia (AML) via the mitogen-activated protein kinase (MAPK) kinase/ERK pathway, which resulted in the daunorubicin resistance of AML cells. This pro-survival role of autophagy has also been supported by other studies showing that autophagy inhibition elevated sensitivity to chemotherapy in multiple myeloma, breast cancer, colorectal cancer and prostate cancer cells (35-38).

Chemotherapy drugs can induce autophagy in leukaemia cells. Li et al (39) indicated that macroautophagy activity in Raji cells was significantly enhanced by arsenic trioxide. 
Consistent with this result, the present study demonstrated that autophagy in K562/ADM and K562 cells was increased with ADM treatment. It was also found that HCQ could inhibit the ADM-induced autophagy response in K562 and K562/ADM cells by restraining the degradation of autophagic vacuoles. HCQ belongs to the 4-amino quinoline family, which is used for antimalarial medications (40). HCQ was employed to inhibit autophagy due to its well-known safety profile. Moreover, when cells were treated with HCQ at nontoxic concentrations, the $\mathrm{IC}_{50}$ values of $\mathrm{ADM}$ in $\mathrm{K} 562 / \mathrm{ADM}$ cells at different time points were significantly reduced, indicating that HCQ could effectively reverse the ADM resistance of K562/ADM cells, and that increased autophagy is one of the mechanisms of multidrug resistance in K562/ADM cells.

In addition to autophagy, it has been suggested that apoptosis is involved in drug resistance (41). Over the years, evidence has accumulated demonstrating that apoptosis and autophagy may share the same signalling pathways, such as p38-MAPK and JNK (42), and there is an interconnected relationship between apoptosis and autophagy (43). For example, a previous study described that autophagy inhibited apoptosis by decreasing Bcl-2-associated death promoter and Bcl-2-like protein 11 expression in hepatocellular carcinoma cells (44). Another study suggested that autophagy was involved in the early stage of apoptosis, leading to the death of acute lymphocytic leukaemia cells (45). The data from the present study demonstrated that the proportion of apoptotic cells induced by ADM was prominently upregulated following pre-treatment with HCQ in K562/ADM cells, which was also confirmed by an increase in caspase-3 activity and the enhanced ratio of Bax/Bcl-2; two classic hallmark proteins for apoptosis. Therefore, autophagy inhibition by HCQ may potentiate ADM-induced apoptosis and contribute to overcoming ADM resistance in K562/ADM cells.

P-gp functions as an ATP-dependent drug ejector pump and decreases the intracellular concentrations of its substrates with different chemical structures (46). Consequently, the enhanced expression of $\mathrm{P}-\mathrm{gp}$ may lead to resistance to a wide range of drugs (47). It has been suggested that P-gp may be involved in regulating molecular metabolism, proliferation and differentiation in cells (48), indicating that P-gp might potentially possess multiple physiological functions. A previous study demonstrated the synergistic roles of P-gp, autophagy and $\mathrm{NF}-\kappa \mathrm{B}$ pathways in the epirubicin resistance of triple-negative breast cancer (49). However, another study suggested that the role of P-gp in the development of multidrug resistance in breast cancer may be independent of autophagy (50). The present study preliminarily demonstrated an association between autophagy and P-gp expression. The results demonstrated that ADM treatment resulted in a significant augmentation of autophagy accompanied by increased mdr1/P-gp expression in K562/ADM cells. In addition, the autophagy inhibitor HCQ markedly inhibited the ADM-induced increase in autophagy, as well as enhancing mdrl/P-gp expression in the cells, and sensitised the drug-resistant cells to ADM. This may mean that inhibition of autophagy attenuates the expression of P-gp, and that P-gp may be involved in autophagic regulation in drug-resistant cells. The true co-regulation and interaction between autophagy and $\mathrm{P}-\mathrm{gp}$ in modifying multidrug resistance requires confirmation in future investigations. In addition, Liu et al (51) suggested that nelfinavir could reverse ADM resistance in K562/ADR cells by inhibiting the P-gp efflux function without affecting P-gp protein and mRNA expression levels. However, the results of the present study indicated that the autophagy inhibitor HCQ might sensitise the drug-resistant cells to ADM by reducing mdrl/P-gp expression at the transcriptional level in cells.

Collectively, the present findings demonstrated that HCQ can reverse ADM resistance in K562/ADM cells by inhibiting autophagy, increasing K562/ADM cell apoptosis and decreasing P-gp expression. It is hypothesised that P-gp may potentially sustain drug resistance in leukaemia cells by participating in the regulation of autophagic activity. The present study revealed a potential novel target for leukaemia intervention and provides further insight into understanding the role of autophagy in the drug resistance of leukaemia cells.

\section{Acknowledgements}

Not applicable.

\section{Funding}

The present study was supported by the National Natural Science Foundation of China grant no. 81541025 (to HLW), the Fundamental Research Funds for the Central Universities grant no. lzujbky-2016-174 (to HLW) and the Natural Science Fund of Gansu grant no. 1208RJZA183 (to HLW). This work was also supported by the National Natural Science Foundation of China grant no. 31571196 (to LW).

\section{Availability of data and materials}

All data generated or analyzed during this study are included in this published article.

\section{Authors' contributions}

FFW performed the examinations, and was a major contributor in writing the manuscript. LW and HLW made substantial contributions to conception and design. WTL interpreted data, translated and revised the manuscript critically for important intellectual content. ZWZ, JC, JY, CMY, MMY, MYW, NZ and XMQ helped to analyze and interpret data. All authors read and approved the final manuscript.

\section{Ethics approval and consent to participate}

Not applicable.

\section{Patient consent for publication}

Not applicable.

\section{Competing interests}

The authors declare that they have no competing interests.

\section{References}

1. Wouters BJ and Delwel R: Epigenetics and approaches to targeted epigenetic therapy in acute myeloid leukemia. Blood 127: 42-52, 2016. 
2. Burnett A, Wetzler M and Lowenberg B: Therapeutic advances in acute myeloid leukemia. J Clin Oncol 29: 487-494, 2011.

3. Gao W and Estey E: Moving toward targeted therapies in acute myeloid leukemia. Clin Adv Hematol Oncol 13: 748-754, 2015.

4. Ramos P and Bentires-Alj M: Mechanism-based cancer therapy: Resistance to therapy, therapy for resistance. Oncogene 34: 3617-3626, 2015

5. Jones PM and George AM: The ABC transporter structure and mechanism: Perspectives on recent research. Cell Mol Life Sci 61: 682-699, 2004

6. Borst P, Evers R, Kool M and Wijnholds J: A family of drug transporters: The multidrug resistance-associated proteins J Natl Cancer Inst 92: 1295-1302, 2000.

7. Bodor M, Kelly EJ and Ho RJ: Characterization of the human MDR1 gene. AAPS J 7: E1-E5, 2005.

8. Ambudkar SV, Dey S, Hrycyna CA, Ramachandra M, Pastan I and Gottesman MM: Biochemical, cellular, and pharmacological aspects of the multidrug transporter. Annu Rev Pharmacol Toxicol 39: 361-398, 1999.

9. Abraham J, Salama NN and Azab AK: The role of P-glycoprotein in drug resistance in multiple myeloma. Leuk Lymphoma 56 26-33, 2015.

10. Danial NN and Korsmeyer SJ: Cell death: Critical control points. Cell 116: 205-219, 2004.

11. Delbridge AR and Strasser A: The BCL-2 protein family, BH3-mimetics and cancer therapy. Cell Death Differ 22: 1071-1080, 2015

12. Zheng JH, Viacava Follis A, Kriwacki RW and Moldoveanu T: Discoveries and controversies in BCL-2 protein-mediated apoptosis. FEBS J 283: 2690-2700, 2016

13. Kroemer G, Galluzzi L and Brenner C: Mitochondrial membrane permeabilization in cell death. Physiol Rev 87: 99-163, 2007.

14. Ghibelli L and Diederich M: Multistep and multitask bax activation. Mitochondrion 10: 604-613, 2010.

15. Kvansakul M and Hinds MG: The Bcl-2 family: Structures, interactions and targets for drug discovery. Apoptosis 20 : $136-150,2015$

16. Indran IR, Tufo G, Pervaiz S and Brenner C: Recent advances in apoptosis, mitochondria and drug resistance in cancer cells. Biochim Biophys Acta 1807: 735-745.

17. Zhi X, Feng W, Rong Y and Liu R: Anatomy of autophagy: From the beginning to the end. Cell Mol Life Sci 75: 815-831, 2017.

18. He C and Klionsky DJ: Regulation mechanisms and signaling pathways of autophagy. Annu Rev Genet 43: 67-93, 2009.

19. Levy JMM, Towers CG and Thorburn A: Targeting autophagy in cancer. Nat Rev Cancer 17: 528-542, 2017.

20. Budini M, Buratti E, Morselli E and Criollo A: Autophagy and its impact on neurodegenerative diseases: New roles for TDP-43 and C9orf72. Front Mol Neurosci 10: 170, 2017.

21. Morandi E, Jagessar SA, t Hart BA and Gran B: EBV infection empowers human $b$ cells for autoimmunity: Role of autophagy and relevance to multiple sclerosis. J Immunol 199: 435-448, 2017.

22. Cosin-Roger J, Simmen S, Melhem H, Atrott K, Frey-Wagner I, Hausmann M, de Vallière C, Spalinger MR, Spielmann P, Wenger RH, et al: Hypoxia ameliorates intestinal inflammation through NLRP3/mTOR downregulation and autophagy activation. Nat Commun 8: 98, 2017.

23. Fulda S: Autophagy in cancer therapy. Front Oncol 7: 128, 2017.

24. Gewirtz DA: The four faces of autophagy: Implications for cancer therapy. Cancer Res 74: 647-651, 2014.

25. Mizushima N, Levine B, Cuervo AM and Klionsky DJ Autophagy fights disease through cellular self-digestion. Nature 451: 1069-1075, 2008

26. Puissant A, Robert G, Fenouille N, Luciano F, Cassuto JP Raynaud $S$ and Auberger P: Resveratrol promotes autophagic cell death in chronic myelogenous leukemia cells via JNK-mediated p62/SQSTM1 expression and AMPK activation. Cancer Res 70 $1042-1052,2010$

27. Wang F, Chen J, Zhang Z, Yi J, Yuan M, Wang M, Zhang N, Qiu X, Wei H and Wang L: Differences of basic and induced autophagic activity between K562 and K562/ADM cells. Intractable Rare Dis Res 6: 281-290, 2017.

28. Liu K, Liu PC, Liu R and Wu X: Dual AO/EB staining to detect apoptosis in osteosarcoma cells compared with flow cytometry. Med Sci Monit Basic Res 21: 15-20, 2015.

29. Livak KJ and Schmittgen TD: Analysis of relative gene expression data using real-time quantitative PCR and the 2(-Delta Delta C(T)) method. Methods 25: 402-408, 2001.
30. Daver N, Cortes J, Kantarjian H and Ravandi F: Acute myeloid leukemia: Advancing clinical trials and promising therapeutics. Expert Rev Hematol 9: 433-445, 2016.

31. Plasschaert SL, de Bont ES, Boezen M, vander Kolk DM, Daenen SM, Faber KN, Kamps WA, de Vries EG and Vellenga E: Expression of multidrug resistance-associated proteins predicts prognosis in childhood and adult acute lymphoblastic leukemia. Clin Cancer Res 11: 8661-8668, 2005.

32. Chen J, Wei H, Xie B, Wang B, Cheng J and Cheng J: Endoplasmic reticulum stress contributes to arsenic trioxide-induced apoptosis in drug-sensitive and -resistant leukemia cells. Leuk Res 36: 1526-1535, 2012.

33. Li CL, Wei HL, Chen J, Wang B, Xie B, Fan LL and Li LJ: Arsenic trioxide induces autophagy and antitumor effects in burkitt's lymphoma raji cells. Oncol Rep 32: 1557-1563, 2014

34. Han W, Sun J, Feng L, Wang K, Li D, Pan Q, Chen Y, Jin W, Wang X, Pan H and Jin H: Autophagy inhibition enhances daunorubicin-induced apoptosis in K562 cells. PLoS One 6: e28491, 2011

35. Riz I, Hawley TS and Hawley RG: KLF4-SQSTM1/p62-associated prosurvival autophagy contributes to carfilzomib resistance in multiple myeloma models. Oncotarget 6: 14814-14831, 2015.

36. Sun Q, Liu T, Yuan Y, Guo Z, Xie G, Du S, Lin X, Xu Z, Liu M, Wang W, et al: MiR-200c inhibits autophagy and enhances radiosensitivity in breast cancer cells by targeting UBQLN1. Int J Cancer 136: 1003-1012, 2015.

37. Zhang H, Tang J, Li C, Kong J, Wang J, Wu Y, Xu E and Lai M: MiR-22 regulates 5-FU sensitivity by inhibiting autophagy and promoting apoptosis in colorectal cancer cells. Cancer Lett 356: 781-790, 2015.

38. Kim SH, Kim KY, Yu SN, Park SK, Choi HD, Ji JH and Ahn SC Autophagy inhibition enhances silibinin-induced apoptosis by regulating reactive oxygen species production in human prostate cancer PC-3 cells. Biochem Biophys Res Commun 468: 151-156, 2015.

39. Li CL, Wei HL, Chen J, Wang B, Xie B, Fan LL and Li LJ: Ebb-and-flow of macroautophagy and chaperone-mediated autophagy in raji cells induced by starvation and arsenic trioxide. Asian Pac J Cancer Prev 15: 5715-5719, 2014.

40. Caminal-Montero L and Suárez-Díaz S: Hydroxychloroquine and antimalarials. J Rheumatol 15: jrheum.190559, 2019.

41. Zhang H, Han D, Lv T, Liu K, Yang Y, Xu X and Chen Y: Novel peptide myristoly-CM4 induces selective cytotoxicity in leukemia K562/MDR and Jurkat cells by necrosis and/or apoptosis pathway. Drug Des Devel Ther 13: 2153-2167, 2019.

42. Sui X, Kong N, Ye L, Han W, Zhou J, Zhang Q, He C and Pan H: P38 and JNK MAPK pathways control the balance of apoptosis and autophagy in response to chemotherapeutic agents. Cancer Lett 344: 174-179, 2014

43. Oral O, Akkoc Y, Bayraktar O and Gozuacik D: Physiological and pathological significance of the molecular cross-talk between autophagy and apoptosis. Histol Histopathol 31: 479-498, 2016.

44. Zhou Y, Sun K, Ma Y, Yang H, Zhang Y, Kong X and Wei L: Autophagy inhibits chemotherapy-induced apoptosis through downregulating bad and bim in hepatocellular carcinoma cells Sci Rep 4: 5382, 2014

45. Yuan N, Song L, Zhang S, Lin W, Cao Y, Xu F, Fang Y, Wang Z, Zhang H, Li X, et al: Bafilomycin A1 targets both autophagy and apoptosis pathways in pediatric B-cell acute lymphoblastic leukemia. Haematologica 100: 345-356, 2015.

46. Rees DC, Johnson E and Lewinson O: ABC transporters: The power to change. Nat Rev Mol Cell Biol 10: 218-227, 2009.

47. Breier A, Gibalova L, Seres M, Barancik M and Sulova Z: New insight into p-glycoprotein as a drug target. Anticancer Agents Med Chem 13: 159-170, 2013.

48. Silva R, Vilas-Boas V, Carmo H, Dinis-Oliveira RJ, Carvalho F de Lourdes Bastos M and Remiao F: Modulation of P-glycoprotein efflux pump: Induction and activation as a therapeutic strategy. Pharmacol Ther 149: 1-123, 2015.

49. Zhang LH, Yang AJ, Wang M, Liu W, Wang CY, Xie XF, Chen X, Dong JF and Li M: Enhanced autophagy reveals vulnerability of P-gp mediated epirubicin resistance in triple negative breast cancer cells. Apoptosis 21: 473-488, 2016.

50. Sun WL, Lan D, Gan TQ and Cai ZW: Autophagy facilitates multidrug resistance development through inhibition of apoptosis in breast cancer cells. Neoplasma 62: 199-208, 2015.

51. Liu W, Meng Q, Sun Y, Wang C, Huo X, Liu Z, Sun P, Sun H, Ma X and Liu K: Targeting P-Glycoprotein: Nelfinavir reverses adriamycin resistance in K562/ADR cells. Cell Physiol Biochem 51: 1616-1631, 2018. 